\title{
AN INTERESTING CASE OF MULTIPLE INGESTED FOREIGN BODIES
}

Balaji Swaminathan ${ }^{1}$, Ruta Shanmugam², V. U. Shanmugam³ ${ }^{3}$ R. G. Mariappan, Dony Manattu Mathaikutty 5

\section{HOW TO CITE THIS ARTICLE:}

Balaji Swaminathan, Ruta Shanmugam, V. U. Shanmugam, R. G. Mariappan, Dony Manattu Mathaikutty. "An Interesting Case of Multiple Ingested Foreign Bodies". Journal of Evolution of Medical and Dental Sciences 2014; Vol. 3, Issue 39, August 28; Page: 9927-9930, DOI: 10.14260/jemds/2014/3286

ABSTRACT: Ingested Foreign bodies are a frequent occurrence in ENT practice. The diagnosis and management are based on clinical and radiological findings. We report a case of 22 year old female who attempted suicide by ingestion of multiple foreign bodies.

KEYWORDS: Ingested; foreign bodies; multiple; depression.

INTRODUCTION: Various types of Foreign Bodies have been reported in the literature in the aero digestive tract and they have always been a challenge to the ENT surgeon. The majority of foreign body (FB) ingestions occur in children.[1] In adults, accidental FB ingestion tends to be food (meat) bolus. Non-food FB ingestions occur more in denture users, incarcerated individuals, and patients with psychiatric disorders or alcohol intoxication. ${ }^{[2-6]}$

When considering foreign bodies in the pharynx and oesophagus, whether the object is potentially penetrating (sharp or corrosive) or non-penetrating is probably the most pertinent consideration. The vast majority of swallowed objects pass through the digestive tract uneventfully. A small (and statistically undeterminable) proportion will impact in the pharynx or oesophagus. Sharp or pointed FBs, animal or fish bones, and magnets increase the risk of perforation. ${ }^{[7]}$

CASE REPORT: A 22 year old female presented with history of accidental ingestion of pin along with her breakfast. She gave history of foreign body sensation in the throat along with difficulty in swallowing and throat pain. X ray neck AP and lateral view showed a foreign body at the level of the cricopharynx.

Fig. 1: X-ray soft tissue neck lateral view showing foreign body at the level of the cricopharynx.

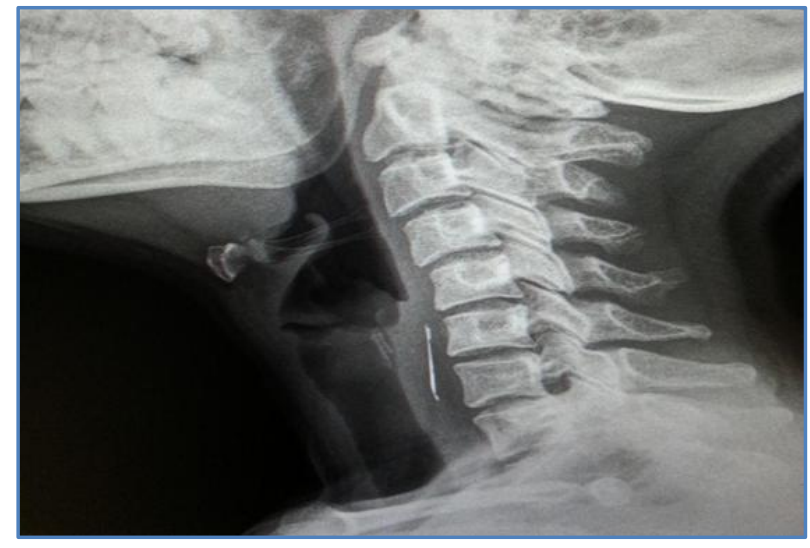

Fig. 1 
Patient underwent foreign body removal under local anaesthesia using Macintosh laryngoscope and Magill's forceps. To everyone's surprise, a broken part of a blade was obtained on laryngoscopy.

Due to unreliable history and with a lot of suspicion, patient was subjected to further radiological examination, which revealed multiple foreign bodies in the gastrointestinal tract.

Fig. 2: X-ray abdomen showing multiple foreign bodies - 1. Piece of blade 2. Single jump clip 3. Bunch of jump clips 4. Hair pin 5. Chain with pendant.

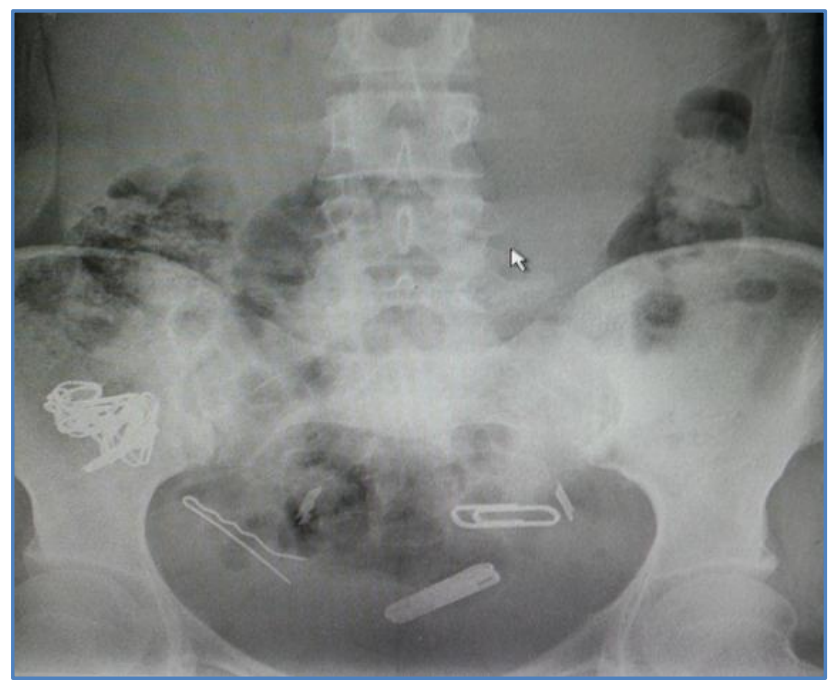

Fig. 2

On repeated enquiry, patient agreed that she had ingested multiple foreign bodies due to a depressive episode. She underwent upper GI endoscopy, which revealed trauma at the level of the right pyriform sinus and the scope was passed up to the first part of duodenum which showed no evidence of foreign body. She was admitted and kept under observation for signs of perforation. After 5 days of observation all the foreign bodies were expelled via faeces.

DISCUSSION: After nose and ear the oesophagus is the commonest site for foreign body impaction. [5]

The majority of foreign objects ingestions occur in paediatrics population with a peak incidence between six months and six years of age while in adults true foreign object ingestion more commonly occurs among those patients with psychiatric disorders, mental retardation or impairment caused by alcohol and old age.[2-6]

Foreign body may be ingested accidentally but also occasionally seen in homicidal or suicidal cases.[7] In the general population, the most common ingested foreign bodies in children are coins ${ }^{[8]}$ but meat bone, marbles, safety pins, hair clips, batteries and screws are also reported while impacted meat or other types of food bolus, fish bone and dentures are common in adults.[2,5,7]

Impaction of a foreign body in the oesophagus causes oedema of the mucosa, and the oesophageal wall becomes weakened. Retention leads to perforation, which is only a matter of time.

Therefore, all foreign bodies retained in the oesophagus should be removed as soon as diagnosed.[5] 
Oesophageal foreign bodies are most frequently located at the level of the cricopharyngeus muscle, the narrowest portion of the oesophagus [9]. The common signs and symptoms in patient with a foreign body that has been retained for less than 24 hour tend to be gastrointestinal and include dysphagia, drooling of saliva, vomiting, gagging and anorexia. Major respiratory symptoms are more common weeks or months after ingestion, such as coughing, stridor, fever, chest pain wheezing, chronic upper respiratory tract infections, pneumonia and haemoptysis. $[3,5]$

Chevalier Jackson's initial description of endoscopic removal of foreign bodies in 1936 revolutionised the treatment options for management of aero digestive foreign bodies. Associated developments in radiology have played an important role in the rationalised and safe management of these cases.[9]

In patients suspected of having ingested or aspirated foreign object, plain two dimensions radiographs of the neck and chest must be taken for pre-operational diagnosis and evaluation. If the history of ingestion of a foreign body which is likely to be radiopaque is given but it is not noted on films of the neck and chest, a radiogram of the abdomen may reveal its progression into the stomach or beyond. ${ }^{[9]}$

Of all ingested FBs brought to the attention of physicians, 80-90\% passes spontaneously, 10$20 \%$ requires endoscopic removal, and $<1 \%$ require surgery. Mortality rates are extremely low $(<$ $0.1 \%$ ). Most adult patients can undergo endoscopy with conscious sedation for endoscopic FB removal.[2-6]

CONCLUSION: Sometimes patient's history can be misleading. Any case of foreign body aspiration or ingestion should be radiologically worked up from neck to abdomen. Imaging studies aid in non-food FB localization and medical documentation. Proper documentation is also important to reduce liability in the event of litigation.[10]

ACKNOWLEDGEMENT: We are thankful to Prof. Dr. P. V. S. Prasad, Dean \& medical Superintendent of Rajah Muthiah Medical College for permitting us to send this manuscript and Dr. Srikanth Nandipati, Lecturer, Department of ENT, for his help and guidance.

\section{REFERENCES:}

1. BK Baral, RR Joshi, BK Bhattarai and RB Sewal. Removal of coin from upper esophageal tract in children with Magill's forceps under propofol sedation. Nepal Med Coll J 2010; 12 (1): 38-41.

2. Awe JAA. Overview of the Management of Swallowed Gastrointestinal Tract Foreign Body. Global Advanced Research Journal of Microbiology Vol. 2 (6) pp. 099-106, June, 2013.

3. Bülent Erbil, Mehmet Ali Karaca, Mehmet Ali Aslaner, Zaur İbrahimov, Mehmet Mahir Kunt, Erhan Akpinar, Mehmet Mahir Özmen. Emergency admissions due to swallowed foreign bodies in adults. World J Gastroenterol 2013 October 14; 19 (38): 6447-6452.

4. Peter Ambe, Sebastian A. Weber, Mathias Schauer, Wolfram T. Knoefel. Swallowed Foreign Bodies in Adults. Dtsch Arztebl Int 2012; 109 (50): 869-75.

5. Raza Muhammad, Zakir Khan, Aisha jamil, Sohail Malik, Tahir Haroon, Farida Khan, Rehman Ghani. Frequency of esophageal foreign bodies and their site of impaction in patients presenting with foreign body aerodigestive tract. European Scientific Journal July 2013 edition vol.9, No.21.

6. S-J Tang. Endoscopic Management of Foreign Bodies in the Gastrointestinal Tract. Video Journal and Encyclopedia of GI Endoscopy. 


\section{CASE REPORT}

7. AM Shivakumar, Ashok S Naik, K B Prashanth, Girish F Hongal, Gaurav Chaturvedy. Foreign bodies in upper digestive tract. Indian Journal of Otolaryngology and Head and Neck Surgery Vol. 58, No. 1, January-March 2006.

8. Surinder K Singhal, Vipin Arora, Arjun Dass. An unusual foreign body of esophagus. Online Journal of Health and Allied Sciences, Volume 9, Issue 1; Jan-Mar 2010.

9. T Losacco, R Cagiano, P Luperto, I Bera, L Santacroce. An unusual foreign body in the upper aerodigestive tract: esophageal obstruction due to bran impaction. European Review for Medical and Pharmacological Sciences 2009; 13: 475-478.

10. Neetu Kumar, Ashish Minocha, David Msuya. Aerodigestive foreign bodies in children, Paediatric Surgery: A Comprehensive Text for Africa, chapter 52, page 329-331.

\section{AUTHORS:}

1. Balaji Swaminathan

2. Ruta Shanmugam

3. V. U. Shanmugam

4. R. G. Mariappan

5. Dony Manattu Mathaikutty

\section{PARTICULARS OF CONTRIBUTORS:}

1. Reader, Department of ENT, Rajah Muthiah Medical College.

2. Professor and HOD, Department of ENT, Rajah Muthiah Medical College.

3. Professor, Department of ENT, Rajah Muthiah Medical College.

4. Professor, Department of ENT, Rajah Muthiah Medical College.

5. Post Graduate, Department of ENT, Rajah Muthiah Medical College.

\section{NAME ADDRESS EMAIL ID OF THE} CORRESPONDING AUTHOR:

Dr. Dony Manattu Mathiakutty, Room 235, PG Medical Mens Hostel, Rajah Muthiah Medical College, Annamalai University, Annamalai Nagar, Chidambaram-608002, Tamilnadu. Email: drlorddmk@gmail.com

Date of Submission: 13/08/2014. Date of Peer Review: 14/08/2014. Date of Acceptance: 20/08/2014. Date of Publishing: 27/08/2014. 